\title{
Should anorectal ultrasonography be included as a diagnostic tool for chronic anal pain?
}

\author{
M. J. García-Montes, F. Argüelles-Arias, S. Jiménez-Contreras, S. Sánchez-Gey, F. Pellicer-Bautista \\ and J. M. Herrerías-Gutiérrez
}

Service of Gastroenterology. University Hospital Virgen Macarena. Sevilla, Spain

\begin{abstract}
Objective: to assess the efficiency of endorectal ultrasound (ERUS) in the study of chronic idiopathic anal pain (CIAP).

Material and method: this is a prospective and descriptive study in which 40 patients, 18 men and 22 women with an average of 47 years, were included. They had chronic anal pain of at least 3 months' duration. A complete colonoscopy was performed in all patients, which found no abnormalities to explain clinical symptoms. Patients with anal fissure and internal hemorrhoids of any degree, perianal suppurative processes, and pelvic surgery were excluded from the study. An ALOKA ProSound SSD-4000 ultrasound console attached to a multifrequency radial transductor ASU-67 (7.5 and $10 \mathrm{MHz}$ ) was used.

Results: one patient could not tolerate the examination. In 8 patients (20\% of cases) alterations were detected during ultrasonography: in 4 patients (10\% of the cases; 1 man and 3 women) internal anal sphincter (IAS) hypertrophy, and in 5 patients ( 4 women and 1 man) a torn sphincter complex. A tear in the upper IAS canal and hypertrophy of the middle anal canal were observed in one patient (1 woman).

Conclusions: ERUS is a simple, economic and useful test to study anorectal pathologies. Although in most studied cases no damage to the anal canal or rectal wall was detected, in a considerable number of patients we observed a thickening of the IAS, a probable cause of anal pain. Therefore, we understand that ERUS should be included in the study of CIAP.
\end{abstract}

Key words: Anorectal ultrasound. Chronic idiopathic anal pain. Internal anal sphincter hypertrophy. Anorectal ultrasonography. Anal pain.
García-Montes MJ, Argüelles-Arias F, Jiménez-Contreras S, Sánchez-Gey S, Pellicer-Bautista F, Herrerías-Gutiérrez JM. Should anorectal ultrasonography be included as a diagnostic tool for chronic anal pain? Rev Esp Enferm Dig 2010; 102: 7-14.

\section{INTRODUCTION}

Chronic anal pain (CAP) is a common pathology in our environment, accounting for $30-40 \%$ of consultations for anal pain (1). CAP is characterized by pain, usually deep and severe, in the middle anal canal, with a variable radiation and which is aggravated by sitting; sleep is not impaired as pain is relieved by lying down (2). A high percentage of patients had undergone previous anal surgery or dystocic deliveries, and many of them had associated psychological disorders $(3,4)$. Some other entities can be included in CAP, like proctalgia fugax, coccygodynia, anus elevator syndrome, descending perineum syndrome, chronic idiopathic anal pain, and pudendal neuralgia.

The diagnosis of chronic idiopathic anal pain (CAP) is mainly based on clinical features, pain radiation and personal history, and, on the other hand, on the absence of any other organic pathology that could justify this condition (5). Hence, ruling out the presence of organic causes, like hemorrhoids, chronic fissures, perianal suppurative conditions and endometriosis of the rectovaginal septum, among other disorders responsible for anorectal pain, is very important. In this way, anorectal ultrasonography (ARUS) is an imaging technique that allows visualization of the rectal walls and the anal canal. Its utility is clearly defined for anorectal cancer staging, in the study of anal incontinence, and for perianal sepsis $(6,7)$.

With ARUS the rectum and the anus may be explored. It is the most effective test to explore the sphincter complex completely, allowing observing the internal anal

\footnotetext{
Received: 06-04-09.

Accepted: 07-10-09.
Correspondence: Federico Argüelles Arias. Servicio de Aparato Digestivo. Hospital Universitario Virgen Macarena. Avda. Dr. Fedriani, 3. 41071 Se- villa.e-mail: farguelles@telefonica.net


sphincter (IAS), a hypoechoic ring 1 to $3 \mathrm{~mm}$ thick depending on age and gender, and the external anal sphincter (EAS), which is observed as an echogenic layer 5 to 8 mm thick (8).

\section{OBJECTIVES}

Chronic idiopathic anal pain (CIAP) has hardly been studied, although its incidence among the general population is quite high, especially among women. In most cases no organic cause is found, which consequently complicates effective treatment. With this study we propose assessing the utility of anorectal ultrasounds for the study of CIAP.

\section{MATERIAL AND METHOD}

A prospective and descriptive study was carried out between 2005 and June 2008, which included 40 patients, 18 men and 22 women, with an average age of 47 years, chronic anorectal pain of unknown origin at the time of inclusion, and duration longer than 3 months. A complete examination was performed on every patient - colonoscopy reaching the cecum, anal examination and rectal digital exam, abdominal ultrasounds, and pelvic magnetic resonance imaging (MRI). In some patients an anorectal manometry was performed, and women also had a gynecologic consultation.

Exclusion criteria were: patients diagnosed with complicated hemorrhoids, anal fissure, perianal suppurative conditions, and hypertrophied anal papillae (Table I).

An ALOKA ProSound SSD-400 ultrasound device with an associated multifrequency radial ultrasound transductor (7.5 and $10 \mathrm{MHz}$ ) ASU-67 was used. Previous to ERUS a cleansing microenema was instilled 2 hours before the procedure. Patients were explored on a stretcher in the left lateral decubitus position with bent knees. In the first place, exploration and rectal exam including sensitivity and sphincter complex tone were carried out. Afterwards the ultrasound transductor was introduced, covered by a latex sheath and lubricated, reaching the rectum, and was then gently removed while images of the rectal wall and the anal canal were

Table I. Selection criteria

\begin{tabular}{cc}
\hline \multicolumn{1}{c}{ Inclusion criteria } & Exclusion criteria \\
\hline $\begin{array}{c}\text { Patients older than } 18 \text { years old with } \\
\text { symptoms of anal pain during more } \\
\text { than } 3 \text { months }\end{array}$ & Patients diagnosed of hemorrhoids \\
& $\begin{array}{c}\text { Patients with anal fissures } \\
\text { Patients with suppurative perianal } \\
\text { processes } \\
\text { Patients with hypertrophied anal papillae }\end{array}$ \\
\hline
\end{tabular}

obtained. All explorations were performed by only one explorer.

All explorations were done systematically: first, a visualization of rectal walls to rule out any damage at this level and possible endometriosis sources on the rectovaginal septum; second, an exploration of the upper anal canal, including the puborectal muscle (PRM) and IAS; third, the middle anal canal, measuring the IAS; and finally the lower anal canal measuring the EAS. IAS measurement was always done in the middle anal canal, at 9 and 6 o'clock. Following Santoro's criteria (9), normality was considered when IAS thickness was between 1 and $3.5 \mathrm{~mm}$ in men and 1.2 to $2.9 \mathrm{~mm}$ in women. Normal EAS thickness was between 2.6 and $8 \mathrm{~mm}$ in men and from 3 to $8.5 \mathrm{~mm}$ in women (10). Therefore, we considered a pathologic homogeneous thickening of the IAS over $3.5 \mathrm{mms}$.

\section{RESULTS}

This test was carried out in all patients except one, as the insertion of the probe resulted in acute pain. In 8 patients (20\% of cases) abnormalities were observed in the ultrasound study. IAS hypertrophy was observed in 4 patients: a 25-year-old man and 3 women of 25, 55 and 67 years of age (Table II). When IAS hypertrophy was detected, we insisted on familiar precedents of CIAP and none of the patient's relatives had a clinical history of that condition. Biopsy was suggested to the patient with the largest hypertrophy to rule out hereditary hypertrophy, but she refused. In these measurements values were higher than $3.5 \mathrm{~mm}$ but not over $5 \mathrm{~mm}$ except for the latter patient, a 55 -year-old woman who reached $5.5 \mathrm{~mm}$. In $50 \%$ of our cases, both women, an anxious-depressive syndrome due to familiar stress was present. In 2 of 4 cases with IAS hypertrophy, treatment with diazepam $(10 \mathrm{mg}$ per day) was started, observing improvement after 3 months of treatment. In 4 patients, anorectal manome-

Table II. Echographic findings in the studied patients

\begin{tabular}{|c|c|c|c|c|}
\hline Patient & $\begin{array}{l}\text { Hypertrophy } \\
\text { IAS }\end{array}$ & $\begin{array}{l}\text { Tearing } \\
\text { IAS }\end{array}$ & $\begin{array}{c}\text { Damage } \\
\text { PBR }\end{array}$ & $\begin{array}{c}\text { Previous clinical } \\
\text { history }\end{array}$ \\
\hline$M(25$ y.o. $)$ & $x$ & & & \\
\hline$F(37$ y.o. $)$ & $x$ & & & Anxious-depressive $S$. \\
\hline$F(67$ y.o.) & $x$ & $x$ & $x$ & Anxious-depressive $S$. \\
\hline$F(55$ y.o. $)$ & $x$ & & & \\
\hline$M(63$ y.o. $)$ & & $x$ & & Hemorrhoidectomy \\
\hline$F(68$ y.o.) & & $x$ & & Obstetric \\
\hline$F(55$ y.о.) & & $x$ & & Obstetric \\
\hline$F(40$ y.o. $)$ & & $x$ & $x$ & Obstetric \\
\hline
\end{tabular}


try was performed increasing basal pressure of the anal canal in 3 of the 4 cases.

In Table II we may observe other ultrasonographic abnormalities - sphincter complex disruptions in 3 women due to obstetric causes and in a man due to hemorrhoidectomy, which caused no fecal incontinence to this day. A 67-year-old woman with IAS hypertrophy had scarring on the puborrectal muscle and a torn upper sphincter due to dystocic delivery. These cases were transferred to the Gynecology Unit to complete their study; no pathology other than above was identified, and no treatment was required (Figs. 1-4).

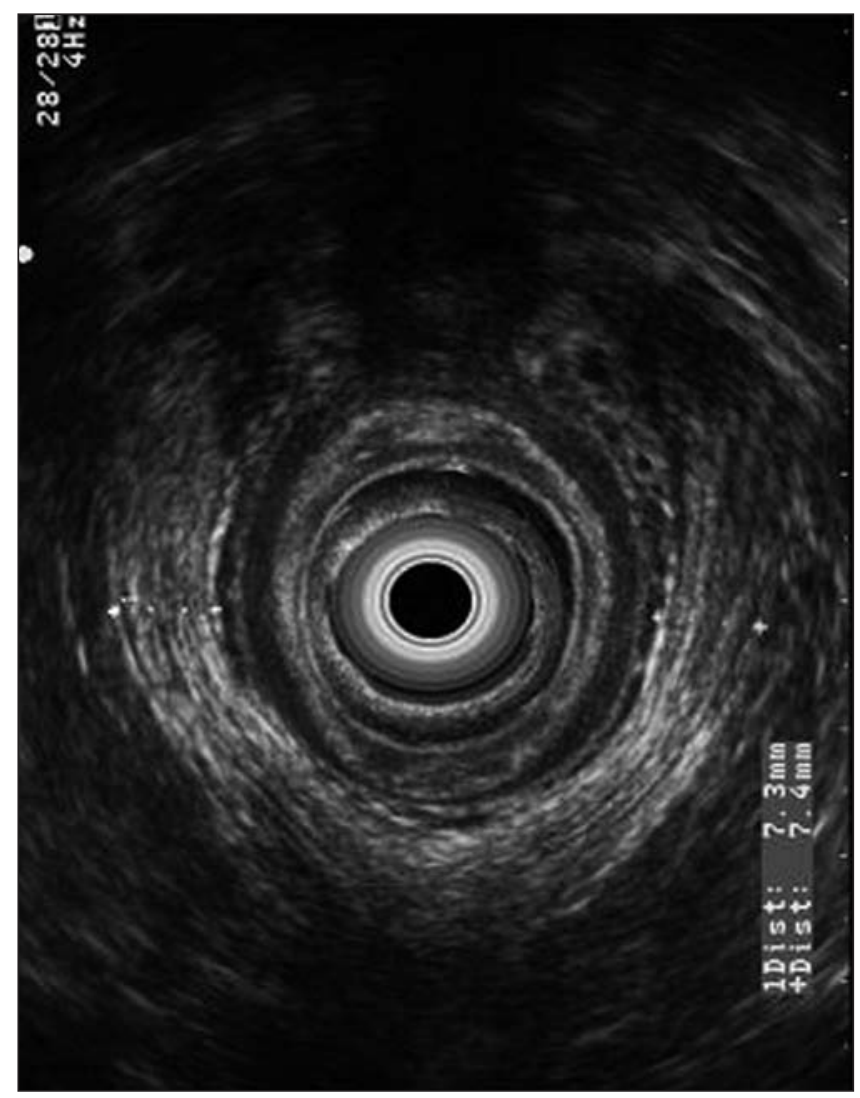

Fig 1. Measurement of the puborectal muscle in a woman with CIAP without anorectal ultrasound abnormalities.

Medición del músculo puborrectal, en mujer con DACl sin anomalías ecográficas.

\section{DISCUSSION}

ERUS is a very useful technique for anal and rectal conditions, with very clear indications in rectal and anal canal cancer staging, perianal sepsis, and anal incontinence (11). The aim of this study, which is merely descriptive, was to determine the utility of this test for chronic anal pain to rule out organic causes, mainly the

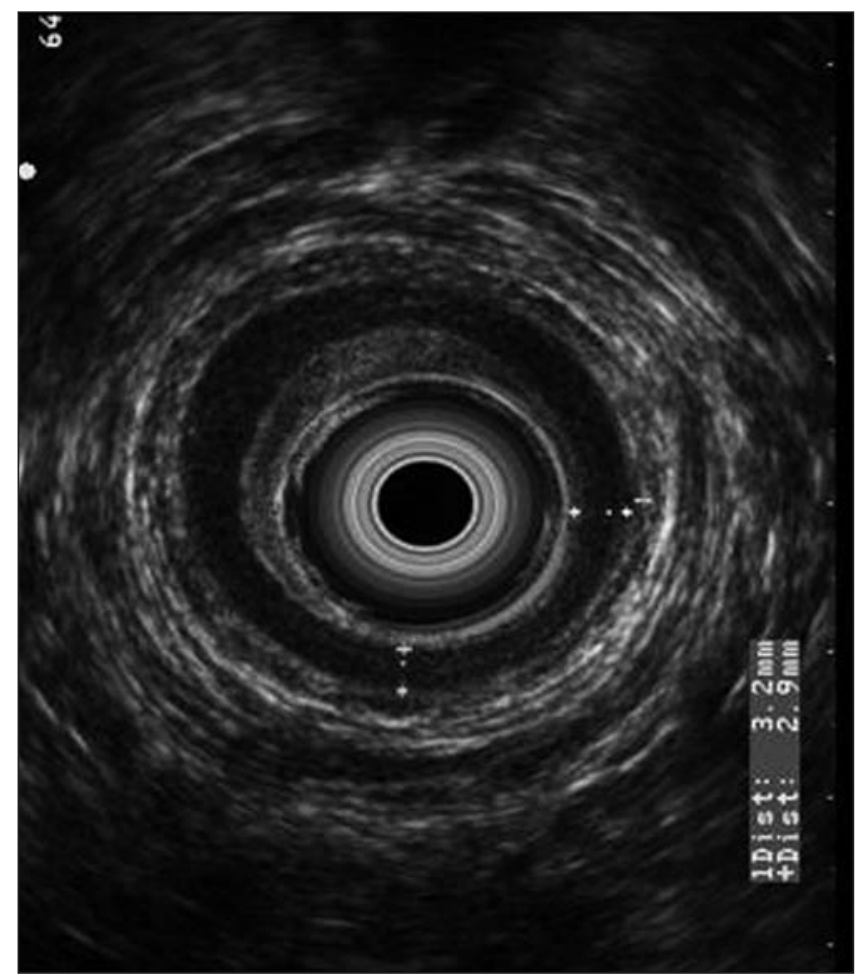

Fig. 2. Measurement of the IAS. Male patient with CIAP without findings on anorectal ultrasounds.

Medición del EAI. Paciente varón con DACl, sin hallazgos en la eco.

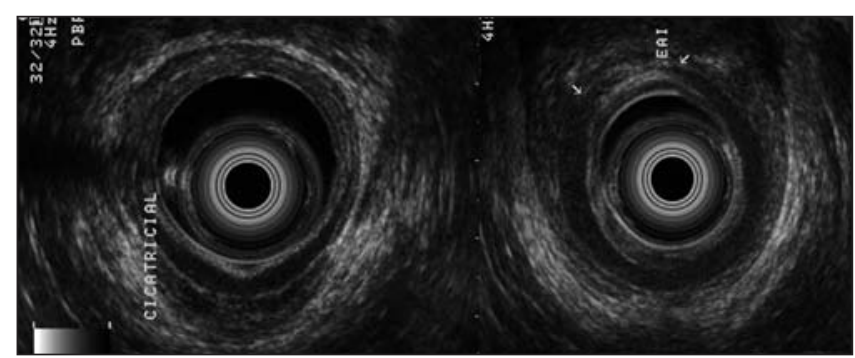

Fig. 3. A woman with CIAP. History of vaginal pain for the past 2 years, and familial stress with anxiety. Complete anterior disruption of the sphincter complex because of a tear. The patient reports no incontinence.

Mujer con DACl. Antecedentes de dolor vaginal desde hace 2 años y estrés familiar con ansiedad. Se observa interrupción completa anterior del complejo esfinteriano por desgarro. No refiere incontinencia.

presence of perianal sepsis (fistulous tract without outward opening or abscesses) and IAS thickening (12). As proved in other studies (13), we believe that endometriosis of the rectovaginal septum must be ruled out, especially if there is a previous history of endometriosis (14).

In our series abnormalities were observed in $20 \%$ of the analyzed cases ( 8 patients). In 4 patients (one man and 3 women) a hypertrophied IAS was observed, and in 5 patients ( 4 women and one man) a torn IAS. Undoubtedly, a torn IAS does not explain chronic anal pain, al- 


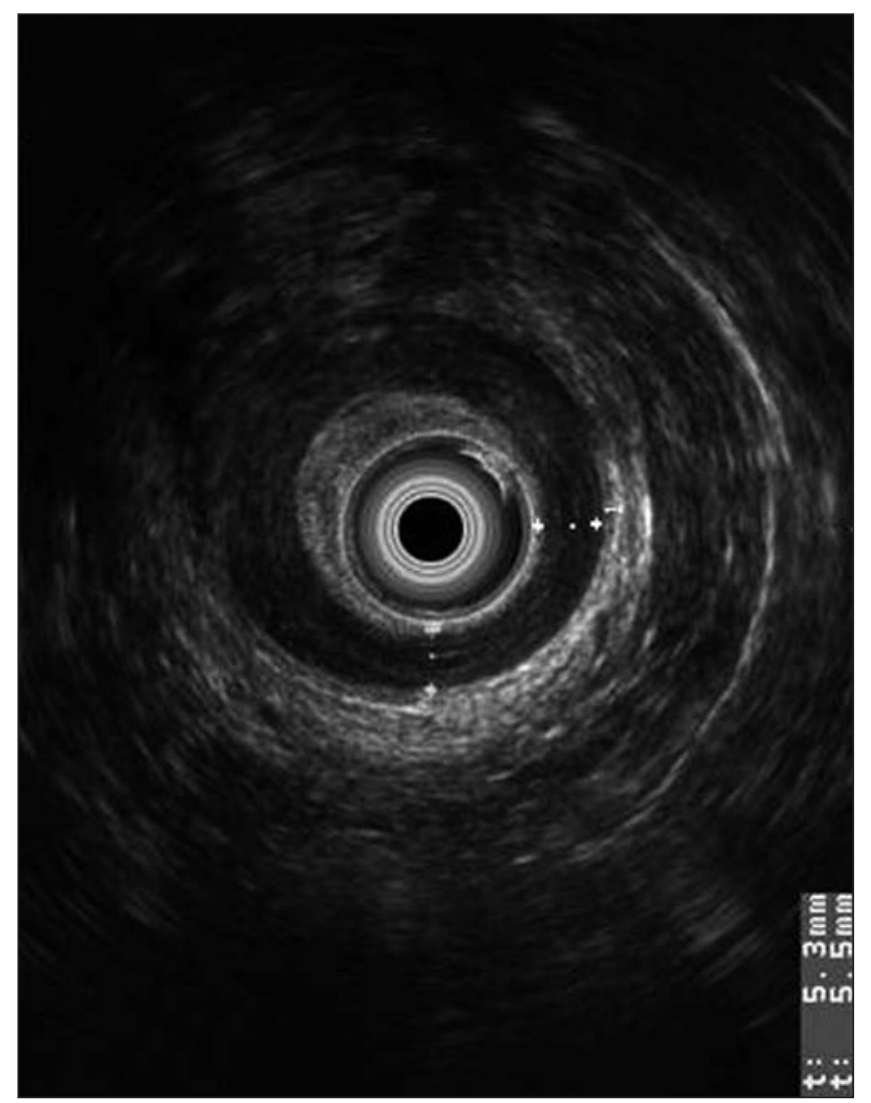

Fig. 4. A woman with IAS hypertrophy (5.2-5.5 mm).

Mujer con hipertrofia del EAl (5,2-5,5 mm).

though we believe that hypertrophied IAS should be considered as a probable cause of anal pain. We considered $3.5 \mathrm{~mm}$ the limit of normality, according to Santoro (9). Nonetheless, it is known that sphincter thickness varies according to gender (15) and, especially, to age, as it increases with age $(16,17)$. Most authors believe that an IAS thicker than $3.5 \mathrm{~mm}$ at any age or in any gender should be considered pathologic (18).

A thickened IAS has been described in some cases of proctalgia fugax. In the study conducted by Gracia Solanas, 15 patients with clinical criteria of proctalgia fugax were assessed with endoanal ultrasounds, which determined a thickening of more than $3.5 \mathrm{~mm}$ on the IAS in 5 cases (19). A diagnosis of thickened IAS as a cause of anal pain allows effective treatment for these patients. In the latter study, these patients benefited from a more aggressive treatment such as sphinterectomy (19). In the study carried out by Sánchez Romero et al. (20) 5 patients with proctalgia fugax were treated with botulinum toxin, with a clear improvement in all of them. It is significant that in none of these patients ERUS detected a hypertrophied anal sphincter. In another study including 198 patients with proctalgia fugax, no lesions were detected with ERUS (21). However, in the study published by Pascual et al. (22) patients with anal pain with or with- out previous surgery were observed. In this study, more than $50 \%$ of patients had a hypertrophied sphincter, this becoming the most frequent ultrasonographic finding associated with spontaneous proctalgia.

Several cases of hereditary hypertrophy of the IAS have already been described, showing ERUS as the most sensitive and specific technique (23-28). It is an infrequent entity but medical or surgical treatment improves most cases. A hypertrophied anal sphincter has also been described in children with chronic constipation (29). In a study published by Christiansen et al. (5) ultrasound studies were performed on 18 patients, 13 women and 5 men with chronic anal pain, and showed that in 12 cases some ultrasound abnormalities were present. In 5 cases, hypoechoic areas were observed on the IAS, in 3 cases hypoechoic areas were observed on the EAS, in 3 cases abnormalities were seen in both sphincters, and in 1 case a thickened IAS was found. We considered that these findings were due to the surgical history of these patients, as most had undergone colorectal surgery (for instance, patients with anal dilations characteristically have hypoechoic areas on the IAS, so their findings are not comparable to ours). Doubtlessly, our study has several limitations: on the one hand, clinical follow-up is not available for all patients, although it is for patients with a thickened IAS. Anorectal manometry was performed in these cases, reporting an increase in anal canal pressure supporting the hypothesis that this induces anal pain. However, our aim was to asses whether ERUS may play a role in this pathology which, although being benign in nature, is very disabling for some patients, with an important decrease in quality of life and a high consumption of health resources.

In conclusion, ERUS is a simple, comfortable, fast, economic and useful technique for anorectal examination. Although a limited series of patients with CAP is presented, we consider that ERUS should be included to rule out organic causes for this disorder, especially sphincter thickening, which could benefit from medical or surgical treatment thus improving a quality of life that would otherwise be doomed. The percentage of patients with hypertrophy is not particularly high but, as this is an economic, simple test, we think that it should be considered for this type of patient.

\section{REFERENCES}

1. Swash M. Chronic perianal pain. En: Henry M, Swash M, editors. Coloproctology and the pelvic floor. London: Butterworths; 1985. p. 388-92.

2. Withehead WE, Wald A, Diamant NE, Enck P, Pemberton JH, Rao SS. Functional disorders of the anus and rectum. Gut 1999; 45 (S-II): II55-9.

3. Magni G, Bertolini C, Dodi G. Douleur périanal chronique: considerations psycho pathologiques characteristiques. Psicopathologie 1986; 19: 170-4.

4. Renzi C, Pescatori M. Psychologic aspects in proctalgia. Dis Colon Rectum 2000; 43: 535-9. 
5. Christiansen J, Bruun E, Skjoldbye B, Hagen K. Chronic idiopathic anal pain: analysis of ultrasonography, pathology and treatment. Dis Colon Rectum 2001; 44: 661-5.

6. De la Portilla F. Anatomía ecográfica normal del conducto anal. En: de la Portilla F, editor. Principios prácticos de la ecografía anal y rectal. Madrid; 2004. p. 65-71.

7. Fernández-Frías AM, Pérez-Vicente F, Arroyo A, Sánchez-Romero AM, Navarro JM, Serrano P, et al. Is anal endosonography useful in the study of recurrent complex fistula-in-ano? Rev Esp Enferm Dig 2006; 98: 573-81.

8. Law PJ, Bartram CI. Anal endosonography: technique and normal anatomy. Gastrointest Radiol 1989; 14: 349-53.

9. Santoro GA, Di Falco G. Basic anatomy. In: Santoro GA, Di Falco G, editors. Atlas of endoanal and endorectal ultrasonography. Milán: Springer; 2004. p. 25-42.

10. Gerdes B, Köhler HH, Zielke A, Kisker O, Barth PJ, Stinner B. The anatomical basis of anal endosonography. A study in postmortem specimens. Surg Endosc 1997; 11: 986-90.

11. García Montes JM, Caunedo Álvarez A, Herrerías Gutiérrez JM. Utility of the endo-rectal ultrasonography with sectorial transducer in the study of rectoanal pathology. Rev Esp Enferm Dig 2001; 93: 615.

12. De la Portilla F. Ecografía anal en situaciones especiales: proctalgias crónicas, estreñimiento y úlcera rectal solitiaria. En: de la Portilla F, editor. Principios prácticos de la ecografía anal y rectal. Madrid; 2004. p. 65-71.

13. Bazot M, Bornier C, Dubernar G, Roseau G, Cortez A, Darai E. Accuracy of magnetic resonance imaging and rectal endoscopic sonography for the prediction of location of deep pelvic endometriosis. Human Reproduction 2007; 1.22: 1457-63.

14. Griffiths A, Koutsouridou R, Vaughan S, Penketh R, Roberts A, Torkington J. Transrectal ultrasound and the diagnosis of rectovaginal endometriosis: a prospective observational study Acta Obstetricia et Gynecologica 2008; 87: 445-8.

15. Regadas FS, Murad-Regadas SM, Lima DM, Silva FR, Barreto RG, Souza MH, et al. Anal canal anatomy showed by three-dimensional anorectal ultrasonography. Surg Endosc 2007; 21: 2207-11.

16. Nielsen MB, Hauge C, Rasmussen OO, Sørensen M, Pedersen JF, Christiansen J. Anal sphincter size measured by endosonography in healthy volunteers. Effect of age, sex, and parity. Acta Radiol 1992; 33: 453-6.

17. Frudinger A, Halligan S, Bartram CI, Price AB, Kamm MA, Winter
R. Female anal sphincter: age-related differences in asymptomatic volunteers with high-frequency endoanal US. Radiology 2002; 224: 417-23.

18. Ramírez Rodríguez JM, Palacios Fanlo MJ, Artigas Marco C, Aguilella Diago V, Martínez Díez M. Anal endosonography for the study of anal canal anatomy: normal images and sonographic variants. Rev Esp Enferm Dig 2001; 93: 364-71.

19. Gracia Solanas JA, Ramírez Rodríguez JM, Elía Guedea M, Aguililla Diago V, Martínez Díez M. Tratamiento secuencial para la proctalgia fugaz. Resultados a medio plazo. Rev Esp Enferm Dig 2005; 97: 491-6.

20. Sánchez Romero AM, Arroyo Sebastián A, Pérez Vicente FA, Serrano Paz P, Candela Polo F, Calpena Rico R. Treatment of proctalgia fugax with botulinum toxin: results in 5 patients. Rev Clin Esp 2006; 206: $137-40$

21. Eckardt VF, Dodt O, Kanzler G, Bernhard G. Anorectal function and morphology in patients with sporadic proctalgia fugax. Dis Colon Rectum 1996; 39: 755-62.

22. Pascual I, García-Olmo D, Martínez-Puente C, Pascual-Montero JA. Ultrasound findings in spontaneous and postoperative anal pain. Rev Esp Enferm Dig 2008; 100: 764-7.

23. Kamm MA, Hoyle CHV, Burleigh DE. Hereditary internal anal sphinter myopathy causing proctalgia fugax and constipation. A newly identified condition. Gastroenterology 1991; 100: 805-10.

24. Celik AF, Katsinelos P, Pead NW. Hereditary proctalgia fugax: Report of a second family. Gut 1995; 36: 581-4.

25. De la Portilla F, Borrero JJ, Rafel E. Hereditary vacuolar internal anal sphincter myopathy causing proctalgia fugax and constipation: a new case contribution. Eur J Gastroenterol Hepatol 2005; 17: 359-61.

26. Konig P, Ambrose NS, Scott N. Hereditary internal anal sphincter myopathy causing proctalgia fugax and constipation: further clinical and histological characterization in a patient. Eur J Gastroenterol Hepatol 2000; 12: 127-8.

27. Martin JE, Swash M, Kamm MA, Mather K, Cox EL, Gray A. Myopathy of internal anal sphincter with polyglucosan inclusions. J Pathol 1990; 161: 221-6.

28. Martorell P, Azpiroz F, Malagelada JR. Hypertrophic myopathy of the internal anal sphincter: a rarely recognized cause of proctalgia. Rev Esp Enferm Dig 2005; 97: 527-9.

29. Keshtgar AS, Ward HC, Clayden GS, Sanei A. Thickening of the internal anal sphincter in idiopathic constipation in children. Pediatr Surg Int 2004; 20: 817-23. 